\title{
Family with probable achondrogenesis and lipid inclusions in fibroblasts
}

\author{
RENATA LAXOVA, P. T. OHARA, M. A. C. RIDLER, and J. A. D. TIMOTHY \\ From Kennedy-Galton Centre, Harperbury Hospital, Shenley, Radlett, Herts.
}

Laxova, R., Ohara, P. T., Ridler, M. A. C., and Timothy, J. A. D. (1973). Archives of Disease in Childhood, 48, 212. Family with probable achondrogenesis and lipid inclusions in fibroblasts. Three stillborn sibs, two males and a female, with probable achondrogenesis, whose parents are first cousins, are reported.

Fibroblast cultures revealed numerous large intracellular lipid inclusions in the two stillborns, which were available for investigation, and these were found to a lesser degree in the mother. No similar inclusions were detected in cultured amniotic cells from a 16-week pregnancy which eventually terminated in the term birth of a healthy female.

The importance of a correct diagnosis and implications for genetic counselling are discussed.

Achondrogenesis is one of the lethal forms of congenital short-limbed achondroplasia-like dwarfism usually resulting in stillbirth or early neonatal death. It resembles thanatophoric dwarfism, though the two can be differentiated by their histological and radiological features.

The first reported case was probably that of Parenti (1936), but it was not until 1952 that Fraccaro, recognizing that his own case was similar to Parenti's, introduced the term achondrogenesis. This was because impairment of cartilage organization and growth was the cardinal histological feature.

Altogether only about 12 sporadic cases of the condition have been reported, and its aetiology is obscure. In a recent report, Saldino (1971) suggested an autosomal recessive mode of inheritance and the present communication records the findings in a family in which a first-cousin marriage produced 7 offspring, 3 of which were stillbirths with what appeared to be achondrogenesis.

\section{Case history}

The mother's first pregnancy, in 1966, terminated at 32 weeks in the stillbirth of a male infant described as 'small and deformed with all his skeletal system showing gross achondroplasia. The head was enlarged with a moderate degree of hydrocephalus'. Diagnosis at necropsy was 'internal hydrocephalus, achondroplasia,

Received 29 June 1972. and prematurity'. Histology of costochondral junction revealed 'abnormal cartilage formation, no bone junction present'. According to the history, no similar stillbirths had occurred elsewhere in the family, the remainder of which is in Pakistan and records are not available. A pedigree is shown in Fig. 1.

In 1967, the mother had a spontaneous abortion at 3 months which was followed in 1968 by the term birth of a healthy girl, weighing $3350 \mathrm{~g}$. The propositus was the result of the fourth pregnancy which had been complicated by hydramnios and lack of fetal movement. The male infant was stillborn at 32 weeks : his birthweight was $1106 \mathrm{~g}$ and length $28 \mathrm{~cm}$. The general appearance (see Fig. 2) was again reminiscent of 'achondroplasia' with gross reduction in limb length (upper $6 \mathrm{~cm}$, lower $7.2 \mathrm{~cm}$ ), particularly in the proximal regions, and with relatively large hands and feet. Carpal and malleolar joints appeared to be absent and knee and elbow mobility was reduced. The head was round, covered with long dark hair, with a cephalic index of 0.89 (length $93 \mathrm{~mm}$, breadth $83 \mathrm{~mm}$, circumference $290 \mathrm{~mm}$ ), large but not bulging fontanelles, and a short neck. The abdomen was distended with no apparent enlargement of liver or spleen. Necropsy revealed no gross visceral abnormalities.

Ten months later, on 5 April 1970, a further pregnancy, again complicated by hydramnios, terminated at 32 weeks in the stillbirth of a female infant whose appearance (Fig. 3) was identical to that of the propositus, apart from the difference in sex. Her birthweight was $1130 \mathrm{~g}$, length $25.5 \mathrm{~cm}$, cephalic index 0.88 (length $91 \mathrm{~mm}$, breadth $80 \mathrm{~mm}$, circumference $288 \mathrm{~mm}$ ), length of limbs: upper $5.5 \mathrm{~cm}$, lower $6.8 \mathrm{~cm}$.

Radiography was performed in both these stillbirths 
Family with probable achondrogenesis and lipid inclusions in fibroblasts

Family $F$.

Family I.

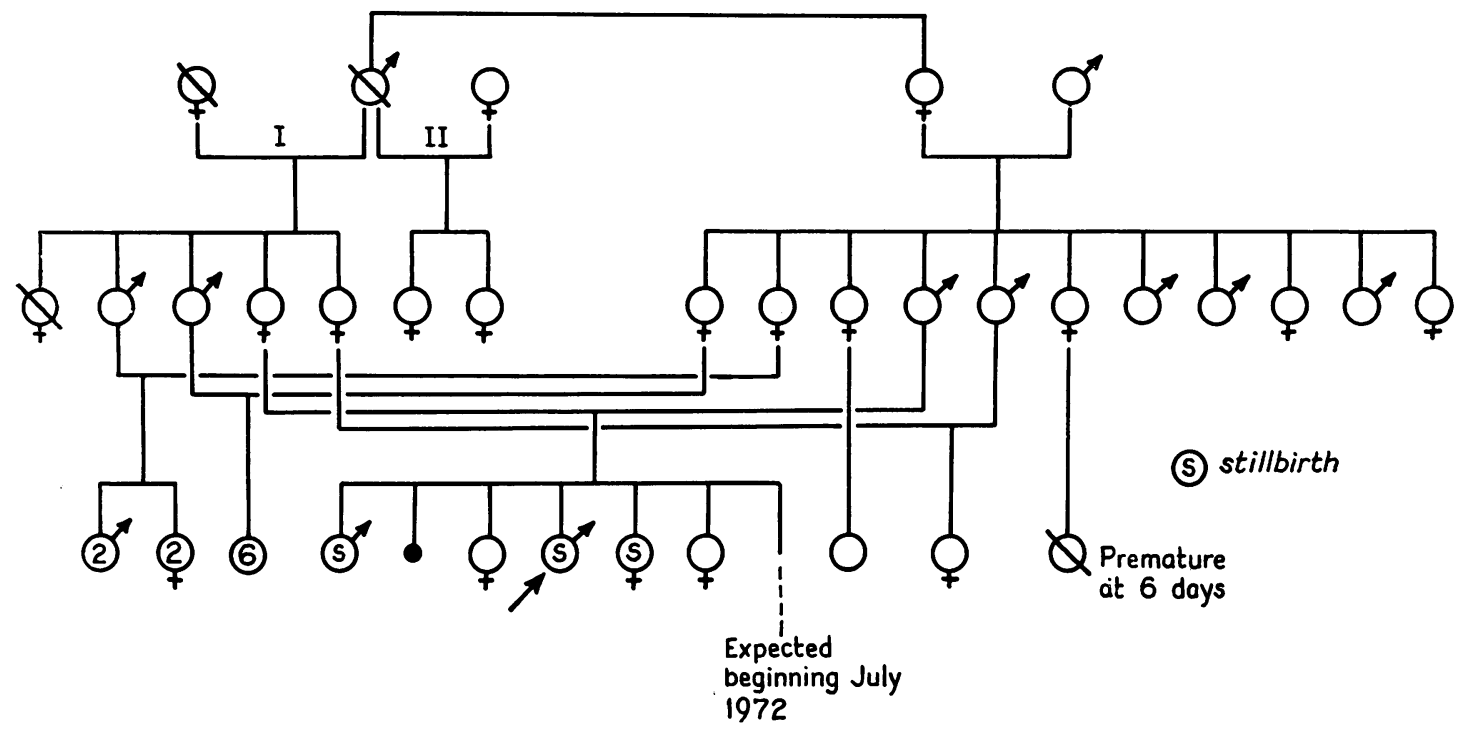

FIG. 1.-Pedigree of family.

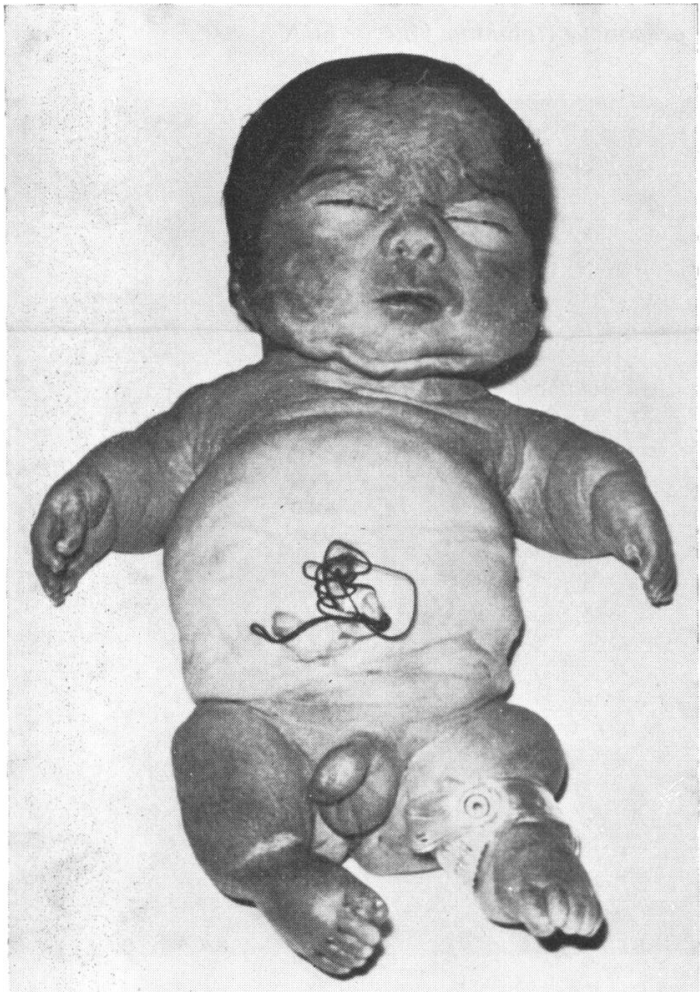

FIG. 2.-Clinical appearance of propositus.

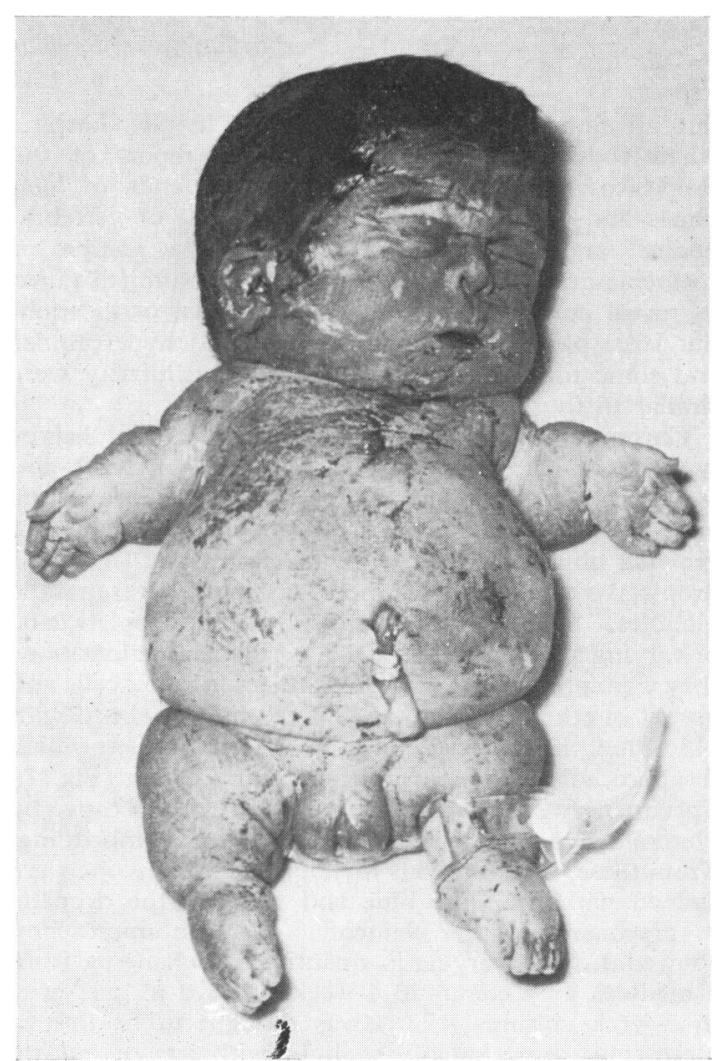

FIG. 3.-Clinical appearance of female stillbirth. 


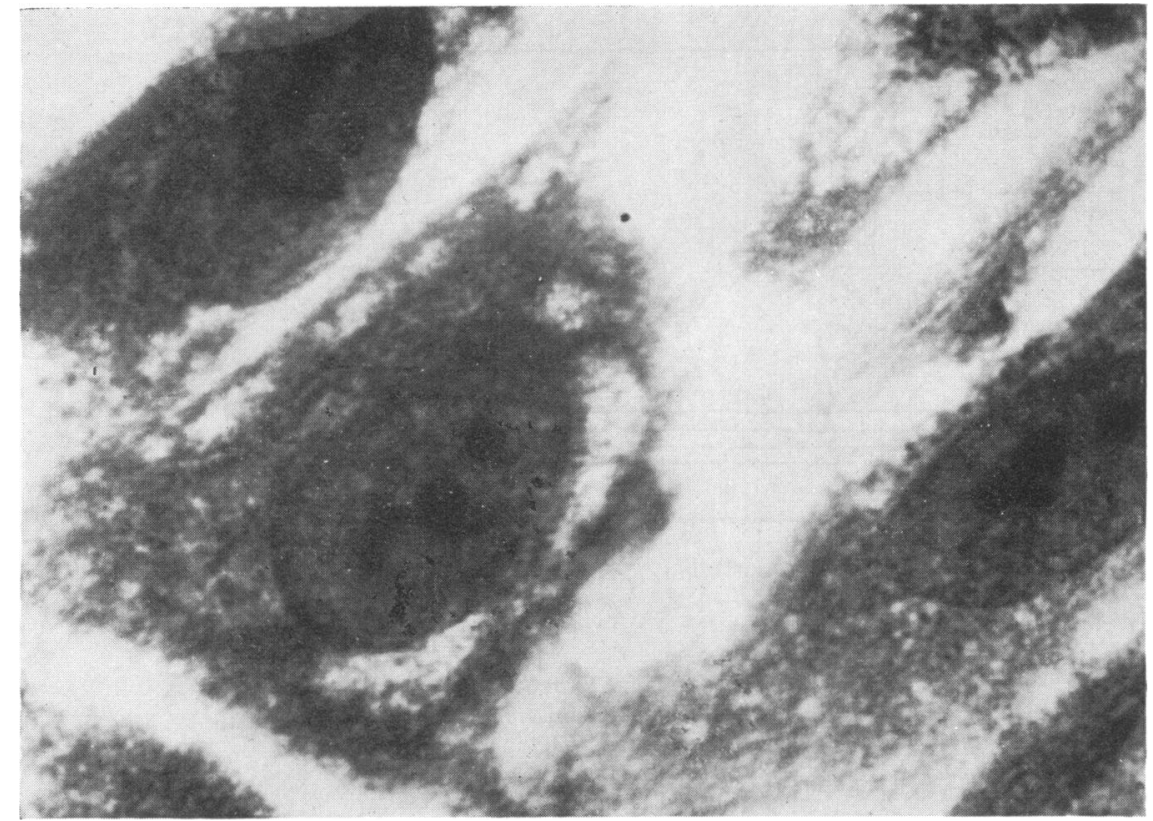

FIG. 4.-Lipid inclusions in fibroblasts of propositus (toluidine blue, $\times 6630$ ).

but all films were irretrievably lost in the hospital where the infants were born. In the report of the propositus 'irregular widened epiphysial ends of long bones and remarkably poor development of vertebral bodies' are mentioned. Histology of a section of costochondral junction from the female stillbirth failed to reveal an adequate area of enchondral ossification, but large parts of the cartilage appeared hypercellular and some focal areas of marked hypercellularity were similar to those seen in achondrogenesis.

Chromosome investigations revealed normal karyotypes from leucocyte cultures from both parents and from necropsy fibroblast cultures from the propositus and the female stillbirth. However, early inspection of growing fibroblasts from both stillbirths revealed lipid droplets which were first noted as markedly refractile globules. Stained preparations showed the droplets to be of varying size, occurring with a perinuclear orientation; they were present in variable numbers in some cells and absent in others. In air-dried preparations stained with Nile Blue, the material appeared as pink droplets which disappeared after treating with organic solvents (Fig. 4). Specimens were prepared for electron microscopy, by gluteraldehyde-osmium fixation and araldite embedding. From these, thick sections for the light microscope were stained with toluidine blue and revealed the droplets as greenish refractile elements. Electron microscopy showed droplets varying in quantity and changing from a medium grey colour in 4-week cultures to pale grey in 8-week cultures. This was thought to be due to increasing saturation of the lipid with age of culture (Fig. 5).

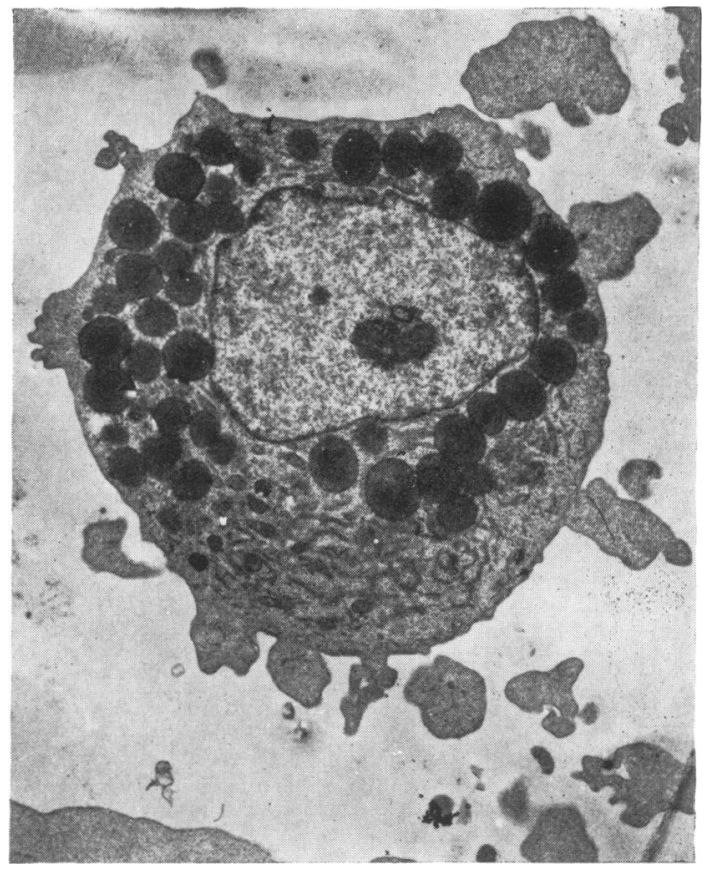

FIG. 5.-Electron micrograph of dark lipid inclusions in fibroblasts of propositus $(\times 4725)$. 


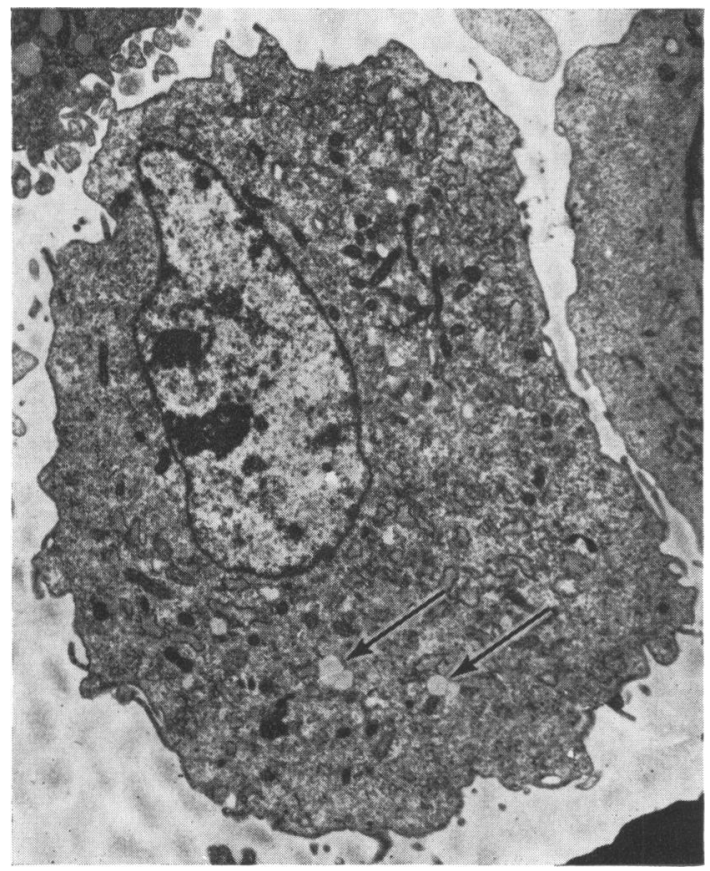

FIG. 6.-Pale lipid inclusions (arrowed) in fibroblasts of control $(\times 4725)$.

The lipid was most marked in cultured fibroblasts from the stillbirths and was present to a lesser degree in the fibroblasts of the mother but not of the father. The latter refused further co-operation when more detailed investigations were requested. Control cultures showed similar lipid material to be present in the fibroblasts from a variety of conditions (mainly chromosomal abnormalities) to about the same extent as in the mother. Additionally, electron micrographic investigation of control cultures showed small isolated droplets (Fig. 6) and a very occasional cell identical with those characteristic of the stillbirth cultures, but never the same number of affected cells. Thus the effect appears as a quantita- tive difference in lipid inclusions rather than as an absolute qualitative one.

In 1971, the mother became pregnant for the sixth time. Fluid and cells were obtained from transabdominal amniocentesis at 16 weeks. Cells were cultured and stained for lipid inclusions, but none was observed. Biochemical investigations of the fluid and maternal serum, given in the Table, revealed no abnormality

Although it was felt that these investigations would not definitely exclude a further stillbirth caused by the same condition, the mother was acquainted with the situation and wished to continue the pregnancy. In July 1971, a healthy female infant was born at 40 weeks.

(Note added in proof. The seventh pregnancy terminated in July 1972 in the term birth of a healthy male.) Amniocentesis was not performed as the parents did not seek antenatal care until the 26 th week.

\section{Discussion}

Findings available in the present family suggest that it represents an example of familial achondrogenesis. Differentiation of the condition from the symptomatically similar thanatophoric dwarfism is made more difficult here by the unavoidably incomplete basic investigations (radiology, histology). Details of the differential diagnosis have been itemized and discussed by Rimoin $e t$ al. (1973), Saldino (1971), and others (Langer et al., 1969; Maroteaux and Lamy, 1968). Findings favouring achondrogenesis in the present case are: hydramnios, and a general clinical appearance strongly reminiscent of stillborn achondroplasia, with short limbs extended almost at right angles and absent skin-folds, greatly reduced body length, poor radiological development of vertebral bodies, and hypercellularity of cartilage in the costochondral junction. The lipid inclusions in the fibroblast cultures of the stillbirths, and to a lesser degree in the mother, remain unexplained; attempts to identify the material were uninformative. It is possible that the aetiology of the condition could involve an hereditary metabolic disorder which

TABLE

Biochemical investigations performed during sixth pregnancy at 16 weeks

\begin{tabular}{|c|c|c|c|}
\hline Amniotic fluid & $\left\{\begin{array}{l}\text { Total phospholipid } \\
\text { Sphingomyelin } \\
\text { Total cholesterol } \\
\text { Free cholesterol } \\
\text { Ester cholesterol } \\
\text { Thin layer chromatography }\end{array}\right.$ & Ganglioside pattern & $\begin{array}{r}41.94 \mathrm{mg} / 100 \mathrm{ml} \\
17 \cdot 20 \mathrm{mg} / 100 \mathrm{ml} \\
2 \cdot 17 \mathrm{mg} / 100 \mathrm{ml} \\
0.90 \mathrm{mg} / 100 \mathrm{ml} \\
1.27 \mathrm{mg} / 100 \mathrm{ml} \\
\text { No abnormality }\end{array}$ \\
\hline Maternal serum & $\left\{\begin{array}{l}\text { Total cholesterol } \\
\text { Free cholesterol } \\
\text { Ester cholesterol } \\
\text { Thin layer chromatography }\end{array}\right.$ & $\left\{\begin{array}{l}\text { Phospholipid pattern } \\
\text { Sphingolipid pattern }\end{array}\right.$ & $\begin{array}{l}240 \mathrm{mg} / 100 \mathrm{ml} \\
60 \mathrm{mg} / 100 \mathrm{ml} \\
180 \mathrm{mg} / 100 \mathrm{ml} \\
\text { No abnormality } \\
\text { No abnormality }\end{array}$ \\
\hline
\end{tabular}


may, in future, be amenable to antenatal detection.

The cases reported by Saldino (1971) were sibs: a female, and a male with a healthy twin brother, whose grandfathers were 'second cousins'. The author's suggestion that an autosomal mechanism of heredity may be involved is supported by the family reported here, where the parents are first cousins. The implications of this factor must be remembered when genetic counselling is requested for healthy parents of apparently 'achondroplastic' stillborn infants. The advice given will be markedly different in cases of genuine achondroplastic stillbirths due to a new mutation, from that in cases of achondrogenesis or thanatophoric dwarfism. Harris and Patton (1971) have suggested that the high mutation and infant mortality rates for achondroplasia are probably overestimated: they show that in their series of 17 infants diagnosed as achondroplasia, no less than 10 were later proved to be examples of thanatophoric dwarfism.

The authors are indebted to the late Professor L. S. Penrose for his advice, to Dr. David L. Rimoin for histo- logical investigations of the costochondral junction, to Miss Anne M. Jéquier for performing amniocentesis, to Professor J. N. Cumings for biochemical investigations, to Mrs. Mary Suddaby for invaluable technical assistance, and to Dr. R. K. de Silva for initially referring the case. R.L. was in receipt of a grant from the Medical Research Council.

\section{REFERENCES}

Fraccaro, M. (1952). Contributo allo studio delle malattie del mesenchima osteopoietico. L'acondrogenesis. Folia Hereditaria et Pathologica, 1, 190.

Harris, R., and Patton, J. T. (1971). Achondroplasia and thanatophoric dwarfism in the newborn. Clinical Genetics, 2, 61.

Langer, L. O., Jr., Spranger, J. W., Greinacher, I., and Herdman, R. C. (1969). Thanatophoric dwarfism. Radiology, 92, 285.

Maroteaux, P., and Lamy, M. (1968). Le diagnostic des nanismes chondrodystrophiques chez les nouveau-nés. Archives Française de Pédiatrie, 25, 241.

Parenti, G. C. (1936). La anosteogenesı (una varietà della osteogenesi imperfetta). Pathologica, 28, 447.

Rimoin, D. L., McAlister, W. H., Saldino, R. M., and Hall, J. G. (1973). The congenital chondrodystrophies-clinical, roentgenographic and histopathological correlations. Pediatric Radiology. (In the press.)

Saldino, R. M. (1971). Lethal short-limbed dwarfism: achondrogenesis and thanatophoric dwarfism. American fournal of Roentgenology, 112, 185.

Correspondence to Dr. Renata Laxova, KennedyGalton Centre, Harperbury Hospital, Harper Lane, Shenley, Radlett, Herts. WD7 9HQ. 